\title{
Analysis and Comparison of the Ecological Niche of Two Endemic Species of the Genus Diploglossus (Sauria: Diploglossidae)
}

\section{Velazco-Pérez $\mathrm{K}^{*}$ and Estrada-Piñero FN}

Department of Zoology, Ecology and Systematics Institute, Cuba

*Corresponding author: Karina Velazco Perez, Ecology and Systematics Institute, Varona street number 11835, between Oriente and Lindero, Havana, Cuba, Tel: (53)7643 8266; Email: karina@ecologia.cu

\section{Research article}

Volume 2 Issue 3

Received Date: May 17, 2019

Published Date: June 12, 2019

DOI: $10.23880 /$ izab- 16000157

\section{Abstract}

Of all the Cuban reptile species, lizards have the greatest richness and diversity. Among them, little is known about the natural history of the species of the genus Diploglossus, so that studies on their ecological niche would provide relevant and novel information about their ecology. Because of that, we proposed to characterize the climatically suitable areas of D. delasagra and D. nigropunctatus and to evaluate the niche overlap between them. We compiled information from 123 georeferenced presence records. Bioclimatic variables of WorldClim were used as predictive variables for the generation of ecological niche models in Maxent program. The final averaged models were binarized to generate presence-absence maps with the ArcGis program. The models obtained were evaluated as useful and excellent according to the difference between the training and testing AUC values, reflecting their high predictive capacity. The contribution of the variables to the resulting models varied between the two species, and in both cases the variables derived from temperature were those with the greatest contribution. The climatically suitable areas completely included the areas of known presence and included other areas. The potential distribution areas of the climate niche for both species showed very different distribution patterns, being higher for D. delasagra (221 $123.84 \mathrm{~km}^{2}$ ) and smaller for D. nigropunctatus (6 $173.82 \mathrm{~km}$ ). The Principal Components Analysis showed a very low niche overlap between the species, being D. delasagra the one with the greatest ecological plasticity and D. nigropunctatus the one with the least, the latter with preference of environments with lower values of seasonality in temperatures and a regime of abundant rainfall all year. The ecological niche breadth was also described using the B1 index in the ENMTools program, and the position and amplitude of the niche along the climatic axes. The Discriminant Analysis showed $95.24 \%$ of correct classifications, so there is no overlap between the ecological niches of both species. In conclusion, $D$. delasagra presents a wide distribution with respect to $D$. nigropunctatus, restricted to the main mountainous massifs of the east of Cuba, and both niches differ in environmental requirements and amplitude, defined by different variables. 


\section{International Journal of Zoology and Animal Biology}

Keywords: Diploglossus; Ecological Niche Modeling; Climatically Suitable Areas; Niche Breadth; Niche Overlap; Cuba

\section{Introduction}

Reptiles are an important element in ecosystems acting as predators controlling the populations of rodents and invertebrates. At the same time, they are prey to other predators, which is why they are so important in the trophic chains of the places where they live, where they play a vital role as secondary consumers and indicators of habitat quality [1,2]. In Cuba three of the four living orders of reptiles (Testudines, Crocodylia and Squamata) are present, for a total of 161 species grouped in 21 families and 32 genera, with an endemism of the $88 \%$, only overcome by amphibians among Cuban vertebrates $[3,4]$.

However, the disappearance of reptiles in the world is unquestionable [2]. The direct and indirect effects of climate change, the fragmentation and loss of habitat, the introduction of exotic species, the very restricted distribution of many of the species and environmental contamination are potential factors in the decline of the natural populations of this zoological group in our country and worldwide [5].

Of all the species of Cuban reptiles, the lizards (Suborder Lacertilia) present the greatest diversity, represented by 108 species and $84.02 \%$ of endemism, been the most diverse group in terms of species shapes and richness [4]. Among them, three belong to the genus Diploglossus, which is included within the Family Diploglossidae: $D$. delasagra, $D$. garridoi and $D$. nigropunctatus (Figure 1). These species are commonly known as "four-legged snakes" because of their morphology, and all three are endemic, but data on their natural history are barely available [6]. In addition, two of them, D. nigropunctatus and D. garridoi are threatened with extinction, so studies of this nature would provide relevant and novel information about the ecology of this group $[7,8]$.
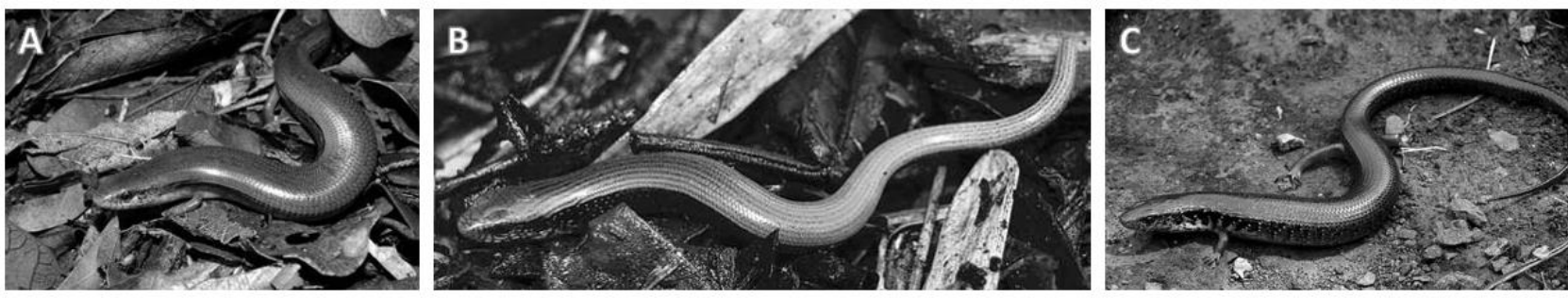

Figure 1: The three species of Diploglossus endemic to Cuba: (A): D. delasagra, (B): D. garridoi and (C): D. nigropunctatus respectively. (C) T. M. Rodríguez-Cabrera, (C) A. Fong and (C) G. Begué, respectively.

For all this, it is necessary to know the current status of their populations, habitat requirements and distribution limits, in order to provide the most appropriate management and establish conservation priorities within the National System of Protected Areas. However, knowledge about the distribution of Cuban reptiles is insufficient $[9,10]$, although recent works have offered lists and geographic representations of the localities where these species live $[4,11]$. In the case of rare species, obtaining this information can be a great challenge, because its detection is positively associated with its abundance, which complicates the efforts to obtain accurate geographic distribution data $[12,13]$.
Velazco-Pérez K and Estrada-Piñero FN. Analysis and Comparison of the Ecological Niche of Two Endemic Species of the Genus Diploglossus (Sauria: Diploglossidae). Int J Zoo Animal Biol 2019, 2(3): 000157.
One of the techniques most used in recent years to generate this type of information are the ecological niche models (ENMs), which allow identifying areas with the appropriate environmental conditions for the presence of a species [13]. The results of studies employing optimal niche theory [14] have shown that some regions are more suitable for a species than other areas, based on factors such as climatic conditions, resource availability and abundance of predators. In Cuba, these tools have been used for lizards of the genus Sphaerodactylus by Velazco, et al. [15].

In the particular case of the three Cuban species of the genus Diploglossus, there are practically no studies that 
address their ecology. In this way, this paper describes for the first time the potential distribution patterns of the ecological niche of two of these species, the adequate environmental requirements for their presence and infers some of their ecological differences. Therefore, this research has as main objectives: 1 . the characterization of the climatically suitable areas of Diploglossus delasagra and D. nigropunctatus; and 2. the evaluation of the niche overlap between these two species.

\section{Materials and Methods}

\section{Description of the Study Area}

The island of Cuba is located in the northwest end of the Caribbean basin, specifically between $74^{\circ} 08^{\prime} 03^{\prime \prime}$ (Punta de Quemado, Maisí) and 85 ${ }^{\circ} 7^{\prime} 07^{\prime \prime}$ (Cape of San Antonio) of west longitude, and the 19 $43^{\prime} 38^{\prime \prime}$ (Punta del

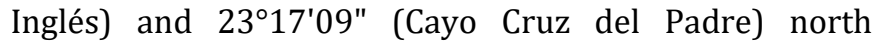
latitude [16]. The main island presents around 107466 $\mathrm{km}^{2}$ of extension and its maximum width is of $191 \mathrm{~km}$ between the north coast of Camagüey and the southeast portion of Granma.

The proximity of Cuba to the North American continent, its relatively little rugged relief, its condition as an island, and the amount of solar radiation that affects its surface, determine its moderate tropical climate $[16,17]$. In addition, hurricanes and cold fronts are frequent. The most notable thermal variations are found in altitudinal gradients, with up to $6^{\circ} \mathrm{C}$ of difference between coasts and mountainous systems [17]. Rainfall is the climatic factor that undergoes the greatest change: only in the rainy season, from May to October $80 \%$ of the total annual rainfall $(1375 \mathrm{~mm})$ is recorded, while in the dry season the other $20 \%$ is registered (344 mm).

The vegetation of Cuba is characterized by an extraordinary richness of species and considerable endemism, mainly in the mountainous regions, where the areas with the greatest forest coverage are located [18]. It is divided into five large groups: forests, shrubs, herbaceous vegetation, vegetation complexes and secondary vegetation. Capote, et al. [19] defined 29 vegetation formations.

\section{Obtaining the Presence Data}

For the modeling, was compiled information from 123 localities with records of the presence of $D$. delasagra and D. nigropunctatus from 34 different sources, among which were included publications, management plans, data from Cuban (BIOECO, CZACC, MNHNCU) and foreign (AMNH, MCZ, USNM) zoological collections, personal communications and field data. The compendium of Rodríguez Schettino, et al. [10] was the main source of consultation. Each of these presence records was georeferenced in decimal coordinates according to the description of the sampling sites (Figure 2), for which cartographic sheets were used in the WGS84 projection, with a scale of 1:50 000. To reduce the effect of the spatial autocorrelation in the presence data, all duplicate data were eliminated for each $1 \mathrm{~km}^{2}$ cell per species, as recommended by Phillips, et al. [20]. The entire process was performed in the ArcMap 10.2 GIS program [21].

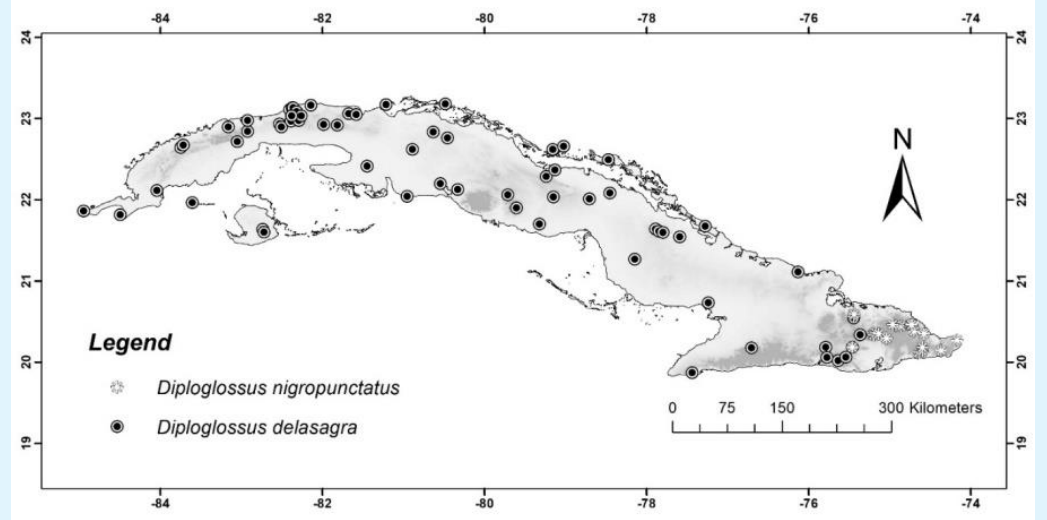

Figure 2: Spatial distribution of the presence points used in the modeling of the ecological niche of Diploglossus delasagra and D. nigropunctatus (Sauria: Diploglossidae) in Cuba. 


\section{International Journal of Zoology and Animal Biology}

\section{Selection of the Area for the Calibration of the Models}

During the modeling process, the presence points are compared with random points within calibration areas (background), to detect the conditions under which a species can potentially live. Taking this into account, random points equidistant $0.5 \mathrm{~km}$ were generated in the entire area occupied by the Cuban territory. In the case of D. delasagra, this whole area was used for the modeling of its ecological niche, whereas with D. nigropunctatus only the Western region was used, to avoid increases in the rate of commission errors (i.e. false positives), [22,23].

\section{Obtaining Environmental Data}

The bioclimatic variables used in the processing were extracted from the WorldClim database with a spatial resolution of $0.8960 \mathrm{~km}^{2}$ and with the WGS84 datum [24]. In addition, the variables vegetable coverage (based on satellite images and a supervised classification analysis) and digital elevation model (DEM) were included. Between five and six variables were selected to model the ecological niche of both species (Table 1), according to the combination of two different criteria: their contribution to the model and the degree of correlation with the others [24]. The contribution of each of the variables to the calibration process of the model was evaluated using the Jackknife method, which calculates the gain in models produced with all the variables except one and then in models that include a single variable [20]. This was calculated with the Maxent $3.3 .3 \mathrm{k}$ program, with 10 replicas. In addition, to avoid the use of variables that provide the same information [25] a Pearson correlation was performed in the Statistica 8 program, and then those that were not correlated with the others were selected (i.e., with $|\mathrm{r}|<0.8$ ), giving priority to the variables defined above as the most important as a result of the Jackknife test [25].

\section{Obtaining Models of Environmental Suitability}

For the preparation of the models of the two species we used their presence data (Figure 2) and the environmental variables that were selected based on the previous analysis (Table 1). As background, the same random points were used within the calibration areas generated in the previous process of evaluating the variables. These models were generated with the program Maxent 3.3.3 k [20], which is based on the principle of maximum entropy, which states that the best approximation to an unknown distribution is one that is more expanded but subject to known restrictions. From this assumption, the algorithm estimates, by means of a set of predictor variables, the distribution that adjusts to those values of the predictive variables in the locations where the presence of the species is known.

\begin{tabular}{|c|c|c|}
\hline Variable & D. delasagra & D. nigropunctatus \\
\hline Mean Diurnal Range (BI02) & $\mathrm{X}$ & \\
\hline Isothermality (BI03) & $\mathrm{X}$ & $\mathrm{X}$ \\
\hline Max Temperature of Warmest Month (BI05) & $\mathrm{X}$ & $\mathrm{X}$ \\
\hline Temperature Annual Range (BI07) & & $\mathrm{X}$ \\
\hline Mean Temperature of Wettest Quarter (BI08) & $\mathrm{X}$ & $\mathrm{X}$ \\
\hline Precipitation of Driest Month (BI014) & & $\mathrm{X}$ \\
\hline Precipitation Seasonality (BI015) & $\mathrm{X}$ & $\mathrm{X}$ \\
\hline Precipitation of Coldest Quarter (BI019) & & \\
\hline
\end{tabular}

Table 1: Variables used in the analysis of the ecological niche of Diploglossus delasagra and D. nigropunctatus (Sauria: Diploglossidae) in Cuba. Marked with an X appear those variables that were chosen for the generation of the models of each species.

For each of the analyzed species, the final models were the average of 50 replications. We used $75 \%$ of the presence data as a training sample to generate the models and the remaining $25 \%$ to validate it. We ran 500 iterations to obtain each model and the resampling method used was Bootstrap, which is very useful when there are not very large sample sizes [26]. The contribution of each of the variables was evaluated again, this time with those that were selected for the definitive models. The rest of the parameters were maintained with their characteristics and recommended values by default [20].

The outputs of these models produce continuous maps where the value of each pixel equals the probability of presence of a suitable environment for the species, given in continuous values between 0 and 1 . For the creation of the presence-absence results (binary), the minimum 
training presence threshold was used as the cut-off threshold, since it is the least restrictive. Peterson, et al. [27] suggests that Maxent generates better models at low threshold values, while when raising them there is an overfitting of the training data. The reclassification in binary maps was done with the program ArcGis ver. 10.1 [21].

\section{Validation of Ecological Niche Models}

The effectiveness of the models was analyzed using the ROC curve (Receiver Operating Characteristic) that represents the relationship between sensitivity and the complement of specificity (1-specificity). Sensitivity is a measure of the rate of true positives and indicates errors of omission, while specificity measures the fraction of negatives classified as presences and represents commission errors [28]. From the ROC curve, the value of the AUC index (area under the curve) was calculated, which measures the ability of the model to discriminate between localities where the species is present or absent. To evaluate the predictive value of the models, the AUC of the training and test data was used and the two were compared to evaluate their differences [29]. For the classification of the models, we followed the criterion of Broennimann, et al. [30], who argue that models with AUC $<0.7$ are considered poor, useful between $0.7 \leq$ AUC $<0.9$, and excellent those with AUC $\geq 0.9$.

\section{Description of the Environmental Suitability Patterns and Characterization of the Known Distribution Areas}

The areas with suitable climatic conditions for the presence of the two Diploglossus species studied were described, based on binary presence-absence maps and trend maps. To estimate the area of potential climatic suitability in each model, the area of each one of the pixels of presence of the species in the final models of potential distribution was added. The species were classified using the PPD (percentage of potential distribution), defined as (number of pixels of presence of the species * 100)/total number of pixels of $\mathrm{Cuba}$, in: species with restricted distribution (0-30\%), species with intermediate distribution (31-59\%) and species with wide distribution (60-100\%).

To characterize ecologically the areas of known presence of each species, the values of all the variables were extracted (Table 1) in the presence points with the ArcGis ver. 10.1 [21]. To achieve a better visualization of the results, reduce the redundancy of bioclimatic variables and decrease the number of parameters, a Principal Components Analysis (PCA) was carried out. The ecological niche breadth was calculated using the B1 index or inverse concentration of Levins in the ENMTools program [31]. From the results of the PCA, the position and amplitude of the niche were also extracted along the climatic axes, similar to the procedure described by Thuiller, et al. [32]. The result of this analysis is the description of the average position of the niche (pCP1, pCP2) in any of the gradients or principal components selected for each species, which represents a measure of the distance between the average conditions used by the species and the average conditions of the study area for the same gradient. For each selected gradient, the variability of the habitat conditions used by each species was estimated, through the calculation of the variance of the coordinates of its presence points in that axis (varCP1, varCP2...varCPn), and this was also considered as a measure of the breadth of the niche. Then, through the descriptive statistics provided by Past 2.17 [33], the environmental ranges that tolerate the species in these areas were calculated [33]. With this same program, a Discriminant Analysis [34] and a Hotelling Test [35] were conducted to evaluate the degree of overlap of the ecological niche of the two species.

\section{Results}

\section{Ecological Niche Models}

The highest value of AUC for training data obtained for the models corresponded to D. nigropunctatus (0.9555), while the lowest was that of $D$. delasagra $(0.782)$, for a general average of 0.8687 . According to these values, $D$. nigropunctatus had excellent performance, and $D$. delasagra had an AUC considered useful for modeling [36]. The test AUC values behaved in the same way as the training values. The differences between the training and test AUC values were between 0.0586 and 0.0726 , which shows that the models were not over-adjusted to the data [37].

According to Jackknife's test the contribution of the variables to the resulting models varied between the two species, and in both cases the variables derived from temperature were those with the greatest contribution. The precipitation of the coldest quarter (BI019) reached the highest percentage of contribution in the construction of D. nigropunctatus model (Table 2). It is followed by the max temperature of the warmest month (BIO5) and the mean temperature of the wettest quarter (BIO8). With regard to the species $D$. delasagra, the variable of greatest 


\section{International Journal of Zoology and Animal Biology}

contribution was the isothermally (BIO3), followed by the max temperature of the warmest month (BIO5) and the precipitation of the coldest quarter (BIO19). In general, in the species D. nigropunctatus a greater dependence of the variables related to the precipitations was observed than in the species $D$. delasagra, which is more widely distributed, and whose contributions of the temperatures variables were significantly higher.

\begin{tabular}{|c|c|c|}
\hline Variable & D. delasagra & D. nigropunctatus \\
\hline Mean Diurnal Range (BIO2) & 5.9 & - \\
\hline Isothermality (BIO3) & 43.0 & - \\
\hline Max Temperature of Warmest Month (BIO5) & 22.9 & 26.6 \\
\hline Temperature Annual Range (BIO7) & - & 5.0 \\
\hline Mean Temperature of Wettest Quarter (BIO8) & - & 16.6 \\
\hline Precipitation of Driest Month (BI014) & 9.5 & 6.9 \\
\hline Precipitation Seasonality (BI015) & - & 4.0 \\
\hline Precipitation of Coldest Quarter (BI019) & 18.7 & 40.90 \\
\hline
\end{tabular}

Table 2: Contribution of environmental variables to the ecological niche models of two Cuban species of the genus Diploglossus (Sauria: Diploglossidae). The contribution values are shown in percentages.

\section{Potential Distribution of the Climatic Niche of the Species of the Genus Diploglossus.}

Because of the process of selection of variables, neither the DEM, nor the vegetation coverage was included for the construction of the ecological niche models, only the bioclimatic variables. Therefore, in the future it will be treated as a climate niche, and the resulting areas as climatically suitable areas (CSA).

The current potential distributions of the climate niche of the studied species coincide spatially with the presence records and include other areas climatically similar to the training ones. The largest CSA corresponded to that of D. delasagra $\left(221123.84 \mathrm{~km}^{2}\right)$ and the lowest was that of D. nigropunctatus (6 $173.82 \mathrm{~km}^{2}$ ) (Figures 3B and 3D). From the percentage values of the potential distribution (PPD), which is no more than a relative measure of the climatic niche dimensions of the species, $D$. nigropunctatus was classified as a species of restricted distribution (DR), and D delasagra showed a wide distribution (DA). It should be taken into account that ENM techniques predict areas that, on average, are climatically adequate for the species, but not the presence of these in those areas [30].
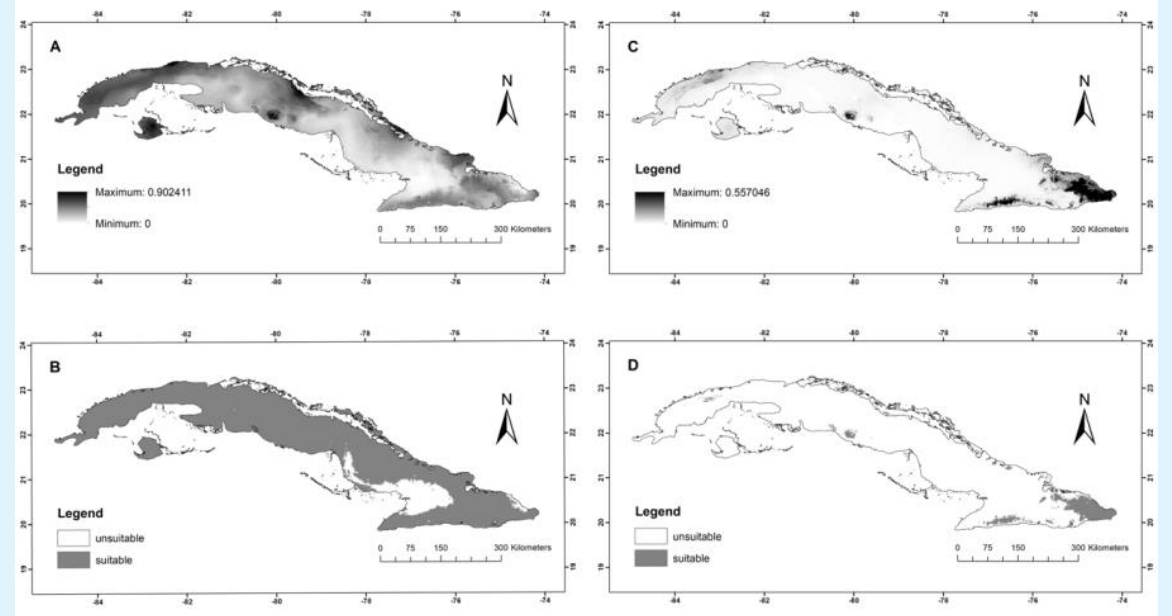

Figure 3: Climatic suitability models for (A) Diploglossus delasagra and (C) D. nigropunctatus, and their climatically suitable areas (B and D, respectively). 
When obtaining the potential distribution maps of the climatic niche for both species of the genus Diploglossus, it was observed that these had very different distribution patterns (Figure 3). The CSA of D. delasagra are continuously distributed throughout the country, except for the southern plain of Camagüey -Manaibón, the plains of Cauto-Guacanayabo, the northern base of the Sierra Maestra and the plains of Moa - Baracoa (Figure 3B). The higher probability of presence coincides with the points of known presence of the species (Figure 2 and 3A). For $D$. nigropunctatus there are small discontinuous CSAs of over prediction towards the center and west of the country (Figure 3D). The highest climatic suitability values were obtained towards the easternmost tip of Cuba and in the main mountain ranges, mainly in Sierra de los Órganos, Sierra del Rosario, Sierra de Trinidad, Sierra de Sancti Spíritus, Sierra Maestra, Sierra de la Gran Piedra and in Nipe-Sagua-Baracoa massif (Figure 3C).

\section{Ecological Niche Breadth}

As for this analysis the 21 original variables were used, in the future it will be referred to as ecological niche. In Tables 3 \& 4 appears the data obtained from the descriptive statistics of the values of the variables in known points of presence. These values allowed characterizing from the environmental point of view the areas of real distribution of the species, as well as the ranges of tolerance of each one, variable to variable. In general, the variables that contributed the most to climate niche models did not varied much in terms of minimums and maximums for each species, except variable BI019 (precipitation of the coldest quarter). In the case of $D$. delasagra this variable ranges from $60.85 \mathrm{~mm}$ to 217.97 $\mathrm{mm}$, while in D. nigropunctatus ranges between $9.20 \mathrm{~mm}$ and $46.60 \mathrm{~mm}$. However, the variables with the lowest contribution to climate niche modeling were more plastic with respect to their limits. For both cases, the variable with the least standard deviation was BIO3 (isothermality) (Tables 3 \& 4).

\begin{tabular}{|c|c|c|c|c|}
\hline Variable & Mean & Minimum & Maximum & Standard deviation \\
\hline $\mathrm{BIO} 1\left({ }^{\circ} \mathrm{C}\right)$ & 24.78 & 19.62 & 24.63 & 1.03 \\
\hline BIO2 $\left({ }^{\circ} \mathrm{C}\right)$ & 9.78 & 8.00 & 11.64 & 0.85 \\
\hline BIO3 & 6.26 & 5.71 & 6.89 & 0.28 \\
\hline $\mathrm{BIO} 4\left({ }^{\circ} \mathrm{C}\right)$ & 19.63 & 14.48 & 21.78 & 2.01 \\
\hline BI05 $\left({ }^{\circ} \mathrm{C}\right)$ & 32.19 & 25.94 & 33.82 & 1.19 \\
\hline BI06 $\left({ }^{\circ} \mathrm{C}\right)$ & 16.67 & 13.15 & 19.33 & 1.02 \\
\hline BI07 $\left({ }^{\circ} \mathrm{C}\right)$ & 1.55 & 1.28 & 1.73 & 0.97 \\
\hline BI08 $\left({ }^{\circ} \mathrm{C}\right)$ & 26.59 & 21.03 & 27.67 & 1.05 \\
\hline BI09 $\left({ }^{\circ} \mathrm{C}\right)$ & 22.25 & 17.59 & 24.93 & 1.14 \\
\hline $\mathrm{BIO} 10\left({ }^{\circ} \mathrm{C}\right)$ & 27.02 & 21.41 & 28.47 & 1.08 \\
\hline $\mathrm{BI0} 11\left({ }^{\circ} \mathrm{C}\right)$ & 220.07 & 175.88 & 241.30 & 9.97 \\
\hline $\mathrm{BIO} 12(\mathrm{~mm})$ & 136.40 & 94.55 & 173.92 & 15.89 \\
\hline $\mathrm{BI013}(\mathrm{mm})$ & 21.49 & 15.62 & 27.44 & 2.80 \\
\hline $\mathrm{BI014}(\mathrm{mm})$ & 3.31 & 1.30 & 6.95 & 1.14 \\
\hline $\mathrm{BI015}(\mathrm{mm})$ & 57.92 & 37.52 & 71.94 & 6.70 \\
\hline $\mathrm{BI016}(\mathrm{mm})$ & 553.81 & 397.18 & 712.77 & 74.97 \\
\hline $\mathrm{BI017}(\mathrm{mm})$ & 122.33 & 60.85 & 213.47 & 33.92 \\
\hline $\mathrm{BIO} 18(\mathrm{~mm})$ & 503.24 & 227.15 & 664.04 & 96.13 \\
\hline $\mathrm{BIO} 19(\mathrm{~mm})$ & 126.47 & 60.85 & 217.97 & 36.57 \\
\hline Vegetal coverage (\%) & 7.31 & 0 & 27.00 & 6.57 \\
\hline DEM (meters asl) & 118.08 & 0 & 1034.00 & 177.24 \\
\hline
\end{tabular}

Table 3: Descriptive statistics of the values of the predictor variables in the areas of known presence of D. delasagra (Sauria: Diploglossidae). 


\section{International Journal of Zoology and Animal Biology}

\begin{tabular}{|c|c|c|c|c|}
\hline Variable & Mean & Minimum & Maximum & Standard deviation \\
\hline $\mathrm{BIO} 1\left({ }^{\circ} \mathrm{C}\right)$ & 22.69 & 20.65 & 26.20 & 1.73 \\
\hline $\mathrm{BIO} 2\left({ }^{\circ} \mathrm{C}\right)$ & 9.16 & 7.44 & 9.99 & 0.53 \\
\hline $\mathrm{BIO3}$ & 6.56 & 6.24 & 6.71 & 0.11 \\
\hline BIO4 $\left({ }^{\circ} \mathrm{C}\right)$ & 15.94 & 14.71 & 17.03 & 0.61 \\
\hline $\mathrm{BIO5}\left({ }^{\circ} \mathrm{C}\right)$ & 29.47 & 27.44 & 32.55 & 1.65 \\
\hline $\mathrm{BIO6}\left({ }^{\circ} \mathrm{C}\right)$ & 15.63 & 13.65 & 20.23 & 1.85 \\
\hline $\mathrm{BIO} 7\left({ }^{\circ} \mathrm{C}\right)$ & 1.38 & 1.19 & 1.50 & 0.64 \\
\hline $\mathrm{BIO} 8\left({ }^{\circ} \mathrm{C}\right)$ & 23.74 & 22.17 & 26.64 & 1.21 \\
\hline $\mathrm{BIO9}\left({ }^{\circ} \mathrm{C}\right)$ & 20.69 & 18.50 & 24.80 & 1.95 \\
\hline $\mathrm{BIO} 10\left({ }^{\circ} \mathrm{C}\right)$ & 24.54 & 22.54 & 27.91 & 1.70 \\
\hline $\mathrm{BI011}\left({ }^{\circ} \mathrm{C}\right)$ & 20.53 & 18.51 & 24.14 & 1.76 \\
\hline BIO12 (mm) & 150.01 & 83.57 & 219.74 & 23.53 \\
\hline BIO13 (mm) & 22.99 & 17.25 & 30.72 & 2.64 \\
\hline BIO14 (mm) & 6.18 & 2.36 & 11.22 & 2.01 \\
\hline $\mathrm{BIO15}(\mathrm{mm})$ & 43.39 & 30.94 & 60.24 & 7.38 \\
\hline BIO16 (mm) & 53.87 & 38.56 & 77.37 & 6.85 \\
\hline BIO17 (mm) & 21.30 & 9.20 & 36.05 & 6.01 \\
\hline BI018 (mm) & 38.56 & 12.85 & 49.38 & 7.70 \\
\hline BIO19 (mm) & 23.15 & 9.20 & 46.60 & 7.81 \\
\hline Vegetal coverage (\%) & 17.33 & 3.00 & 30.00 & 8.79 \\
\hline DEM (meters asl) & 517.76 & 13.00 & 825.00 & 268.32 \\
\hline
\end{tabular}

Table 4: Descriptive statistics of the values of the predictor variables in the areas of known presence of $D$. nigropunctatus (Sauria: Diploglossidae).

\begin{tabular}{|c|c|c|c|}
\hline PC & Eigen value & \% variance & \% cummulative variance \\
\hline 1 & 63589.00 & 53.02 & 53.02 \\
\hline 2 & 46741.70 & 38.97 & 91.98 \\
\hline 3 & 7170.15 & 5.98 & 97.96 \\
\hline 4 & 1075.66 & 0.90 & 98.86 \\
\hline 5 & 749.62 & 0.62 & 99.48 \\
\hline 6 & 417.64 & 0.35 & 99.83 \\
\hline 7 & 87.09 & 0.07 & 99.90 \\
\hline 8 & 61.02 & 0.05 & 99.96 \\
\hline 9 & 32.41 & 0.03 & 99.98 \\
\hline 10 & 11.53 & 0.01 & 99.99 \\
\hline 11 & 3.62 & 0 & 99.99 \\
\hline 12 & 3.13 & 0 & 100.00 \\
\hline 13 & 2.28 & 0 & 100.00 \\
\hline 14 & 1.00 & 0 & 100.00 \\
\hline $\mathrm{Z}$ & 0.33 & 0 & 100.00 \\
\hline 16 & 0.14 & 0 & 100.00 \\
\hline 17 & 0.05 & 0 & 100.00 \\
\hline 18 & 0.02 & 0 & 100.00 \\
\hline 19 & 0 & 0 & 100.00 \\
\hline
\end{tabular}

Table 5: Own values, percentage of variability explained and accumulated according to the PCA performed with the bioclimatic variables for Diploglossus delasagra and D. nigropunctatus (Sauria: Diploglossidae). 
Table 5 shows the Eigenvalues or magnitude of each vector of the Principal Components Analysis (PCA), together with the percentage of variability explained and accumulated by each of them. In this table, it can be observed that it is possible to adequately represent the variability of the data with the first two components or eigenvectors, with ca. $91.98 \%$ of the total variability represented.
The first principal component, which reflects $53.02 \%$ of the total variation in the distribution of the species, represents a temperature seasonality gradient since the variable with the highest participation was BIO4, in a positive direction. The second gradient, which explains the $38.97 \%$ of the variation, includes the annual precipitation since it received a greater positive contribution from the variable BIO12 (Figure 4).

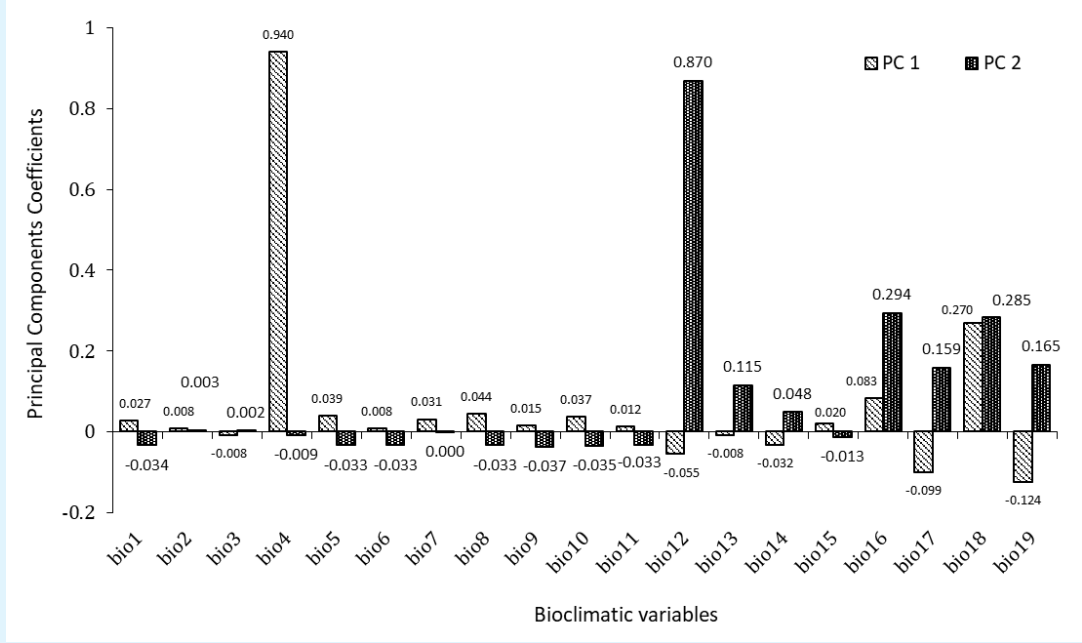

Figure 4: Weight of the bioclimatic variables in the main components 1 (PC 1) and 2 (PC 2) of the climatic fundamental niche of Diploglossus delasagra and D. nigropunctatus (Sauria: Diploglossidae).

From the dispersion ellipses for 95\% of the data (Figure 5), the mean position of the niche of each species was determined in the both gradients obtained (pCP1 and pCP2), which represents a measure of the distance between the average conditions used by the species and the average conditions of the study area (Cuba) for each gradient. In addition, the variance of the coordinates of each point of presence in the given component was calculated to estimate the variability of the habitat conditions used by each species, that is, the niche breath in each climatic gradient (varCP1 and varCP2). In the graphical representation of the distribution of both species with respect to the first two principal climatic components (Figure 5), at first sight it is observed that $D$. delasagra is more eurioic than $D$. nigropunctatus, since its climatic niche has a central tendency (pCP1 $=104.0$; pCP2 $=-30.9$ ) and at the same time greater amplitude (varCP1 = 39517.32 , varCP2 $=36$ 579.42). The data of $D$. nigropunctatus show a smaller dispersion in the $\mathrm{X}$ axis (varCP1 = 5 203.21), being located towards its negative region $(\mathrm{pCP} 1=-311.90, \mathrm{pCP} 1=92.69)$, so it can be considered a marginal or specialist species with preference for environments with lower values of seasonality in temperatures and a regime of abundant rainfall throughout the year ( $\operatorname{varCP} 2=68552.7288$ ).

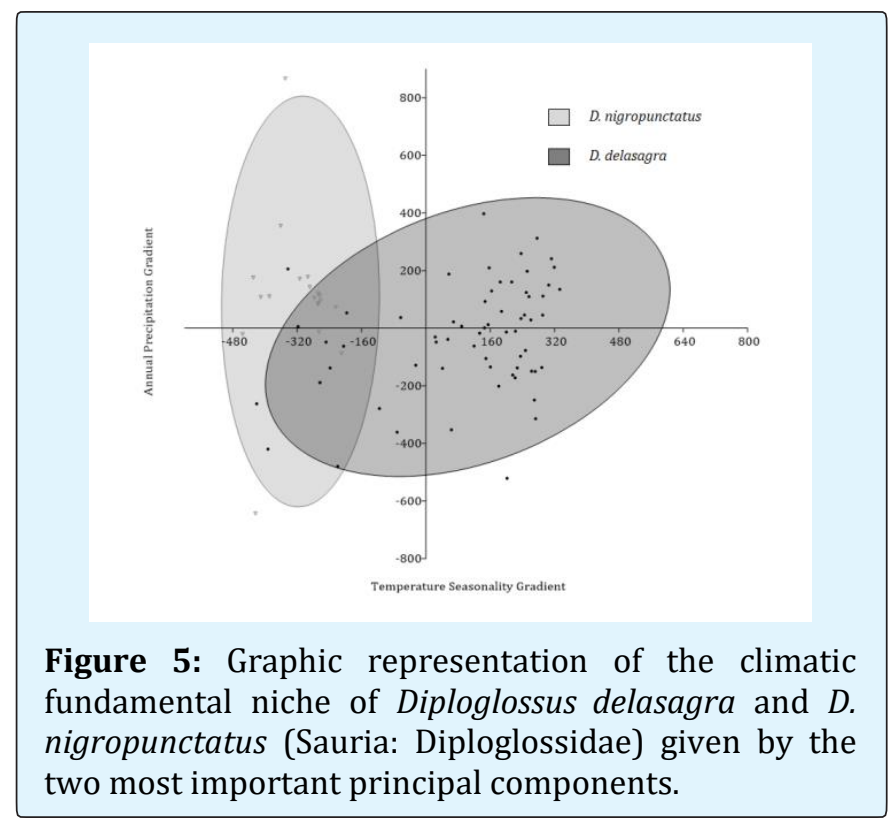


At the same time, based on Maxent's predictions about the climatic suitability of the habitats of each species, we calculated the inverse concentration B1 with the ENMTools program [38], which is a traditional estimate of niche breadth. For the $D$. delasagra species a high amplitude value was obtained (B1=0.7554), while for the species $D$. nigropunctatus the value was much lower (B1=0.0786). These results correspond to the previous ones, and to those obtained from the PPD.

\section{Analysis of Ecological Niches Overlap}

As a result of the Discriminant Analysis, $95.24 \%$ of correct classifications were obtained, that is, only $4.76 \%$ of the presence points of both species could not be discriminated, since they represent localities with similar environmental conditions (Figure 6). In the same way, highly significant differences were obtained with Hotelling T2 (T2 $=363.42, \mathrm{~F}=13.085, \mathrm{p}<0.01$ ), which confirms that there is no overlap between the ecological niches of these two species.

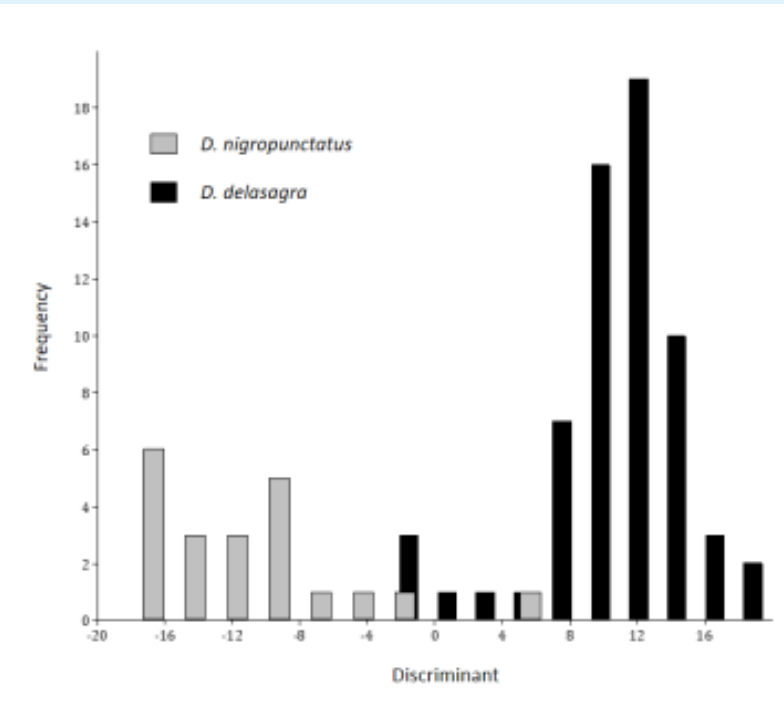

Figure 6: Graph result of the Discriminant Analysis of the ecological niches overlap of Diploglossus delasagra and D. nigropunctatus species (Sauria: Diploglossidae) in their known presence areas.

\section{Discussion}

The climatic suitability models obtained for the two species showed a predictive capacity that can be considered useful to excellent, since the AUC values for training data were above 0.75 , according to the classification of Broennimann, et al. [36]. These predictive capacity values, according to this author, provide high reliability to the obtained models as has been demonstrated by others in similar studies [39-41]. The models generated for the specialist species tended to have a greater predictive power with respect to those of the generalists, as has been observed in other investigations, in which the precision of the model improves when the focal species has a small geographic range $[12,41]$.

Velazco-Pérez K and Estrada-Piñero FN. Analysis and Comparison of the Ecological Niche of Two Endemic Species of the Genus Diploglossus (Sauria: Diploglossidae). Int J Zoo Animal Biol 2019, 2(3): 000157.
Even though the WorldClim database provides 19 bioclimatic variables for modeling, in this research two other topographic and vegetation variables were chosen, which could influence some ecological parameters of both Diploglossus species, and which have been widely used in similar studies [42-45]. According to Jiménez-Valverde, et al. [28], using only bioclimatic variables is an error since, often, the distribution of the species is strongly conditioned by geographical aspects.

The contribution of the variables to the resulting models varied between the two species (Table 2), and in all cases the variables derived from temperature were those with the greatest contribution. The precipitation of the coldest quarter (BIO19) was the variable that reached the highest contribution percentage in the construction of the D. nigropunctatus model, as did max temperature of 


\section{International Journal of Zoology and Animal Biology}

the warmest month (BIO5) and the mean temperature of the wettest quarter (BIO8). Meanwhile, with the species $D$. delasagra the variable with the highest contribution was the isothermality (BIO3), followed by the mean temperature of the wettest quarter (BIO8) and the precipitation of the coldest quarter (BI019). This coincides with that was found by Clusella-Trullas, et al. [46], which state that two of the components of the fitness of the squamate ectotherms (mainly lizards and snakes), the maximum critical temperature and the optimum temperature, are more related to the variation in temperature and rainfall, than to the average temperature conditions. Due to this, the variation in temperature, either the diurnal or interannual range between the extreme values, is the major determining factor in their performance and, therefore, the distribution of this zoological group, mainly under the conditions of the tropics.

According to other investigations in lizards of the genus Sphaerodactylus [15] and the results obtained from this work, there seems to be a trend towards the annual temperature range (BIO7) being one of the variables with the greatest influence on the distribution of the species of the Eastern region, as it is the case of D. nigropunctatus. In the same way, the middle diurnal range (BIO2) seems to be one of the variables of greater contribution in species of wide distribution and great ecological plasticity as $D$. delasagra.

The distributions of the climatic niches of the two species of the Diploglossus genus studied coincided in a large extent with the distributions offered in lists and geographic representations of the localities where these species live $[10,47]$. As for the extension of the CSA, we obtained values similar to those of Fong, et al. $[48,49]$, which reports an extension of occurrence of $214902 \mathrm{~km}^{2}$ for D. delasagra and $6314 \mathrm{~km}^{2}$ for D. nigropunctatus. The classification by the PPD resembles the classification of the Cuban herpetofauna according to different geographic distribution patterns (PDG, in Spanish) of Rodríguez Schettino, et al. [41] for the case of D. nigropunctatus, which they consider Regional. However, it does not coincide with $D$. delasagra, which they also classify as Regional, but which in the present contribution was classified as a wide distribution species.

Regarding the niche breadth (index B1), D. delasagra obtained a value almost 100 times greater than that of $D$. nigropunctatus. These results reaffirm that $D$. delasagra has a wider niche, that is, it has a greater ecological plasticity; while $D$. nigropunctatus lives in narrower environmental conditions, that is to say that it is less tolerant or stenoic. These results correspond to their distribution patterns. According to Martínez Reyes, et al. [50], D. nigropunctatus is a species with subterranean habits, so it requires very specific environmental conditions to live, more stable from the climatic point of view.

D. delasagra, according to Schwartz, et al. [51] is a mesophilic species, that is, it lives close to the ground, under leaf litter looking for humidity and low temperatures, so it was expected that variables such as BI012 (annual precipitation), and BI016 (precipitation of the rainiest quarter) had high mean values that directly influenced the habitat of this species. It is possible that this behavior allows it to tolerate a greater range of temperatures throughout the year, as evidenced by the results of amplitude and position of the niche obtained here. In the case of $D$. nigropunctatus, even little is known about its ecology and habitat preferences [6]. Its underground habits reported by Martínez Reyes, et al. [50], corresponds to the tendency described here to inhabit places with an abundant annual water regime, which could favor the adequate conditions of soil moisture that this species needs for its penetration. In the case of the results of the descriptive statistics (mean, minimum, maximum and standard deviation), the variables that contributed the most to the ecological niche models did not vary much with respect to their minimum and maximum values, with the exception of BI019 (precipitation of the coldest quarter), which presented a large oscillation between $60.85 \mathrm{~mm}$ and $217.97 \mathrm{~mm}$ in $D$. delasagra, and between $9.20 \mathrm{~mm}$ and $46.60 \mathrm{~mm}$ in $D$. nigropunctatus. Other interesting results that were obtained were with the variable DEM, which in the case of D. delasagra oscillated from 0 to $1034 \mathrm{~m}$ above sea level (with the mean at $118,08 \mathrm{~m}$ above sea level), in correspondence with its generalist character, because it does not seem to have a marked preference for a certain height. However, D. nigropunctatus models located it almost exclusively at elevations, in correspondence with the mean values of DEM $(517.76 \mathrm{~m})$. These values are similar to those reported by Fong, et al. [52], which locates the latter species between 150 and $800 \mathrm{~m}$ above sea level. The highest vegetal coverage values for this species with respect to those of $D$. delasagra, coincide with the consistent forest habitats where Fong, et al. [7,8] have collected $D$. nigropunctatus: montane, submontane and low altitude rainforest, although it can also appear in secondary vegetation. Meanwhile, it is possible that $D$. delasagra exploits more open habitats, such as forest 


\section{International Journal of Zoology and Animal Biology}

edges, gardens and orchards [6], as confirmed by our results.

The Discriminant Analysis confirmed the great difference that exists between the ecological niches of these two species, since they only presented a $4.76 \%$ of overlap. Incorrectly classified points of presence may correspond to sympatric localities between these two species, which has never before been described in the literature. The results of the Hotelling Test corroborated that there is practically no overlap between the fundamental niches of D. delasagra and D. nigropunctatus. These results support the conclusions of Losos, et al. [53] who states that phylogenetically related species do not necessarily have ecological similarities [54].

\section{Conclusion}

The distribution of the climatically suitable areas of $D$. delasagra is wide in relation to that of D. nigropunctatus, which are restricted to the main mountainous massifs of the east of the country. The ecological niches of both species differ in their environmental requirements and their breadth, and they are defined by different bioclimatic variables, so there is little overlap between them.

\section{Acknowledgement}

We wish to thank the anonymous referees for their review of the article and valuable suggestions.

\section{Funding}

This investigation was supported under the auspices of two projects: "Colecciones zoológicas, su conservación y manejo III", and "Distribución potencial actual y futura de especies de la flora y la fauna de Cuba: explorando efectos del cambio climático sobre la biota terrestre", by the Institute of Ecology and Systematics, Cuba.

\section{References}

1. Velazco K, Rodríguez Schettino L (2011) List and bibliography of the geckos (Gekkota: Gekkonidae, Phyllodactylidae, Sphaerodactylidae) of Cuba. Revista Colombiana de Ciencia Animal 3(1): 1-10.

2. Gibbons JW, Scott DE, Ryan TJ, Buhlmann KA, Tuberville TD, et al. (2000) The Global Decline of Reptiles, Déjà Vu Amphibians. Bio Science 50(8): 653666.

Velazco-Pérez K and Estrada-Piñero FN. Analysis and Comparison of the Ecological Niche of Two Endemic Species of the Genus Diploglossus (Sauria: Diploglossidae). Int J Zoo Animal Biol 2019, 2(3): 000157.
3. Torres J, Rodríguez-Cabrera TM, Marrero R (2017) Reptiles. In: Mancina CA, Cruz DD, (Eds.), Diversidad biológica de Cuba: métodos de inventario, monitoreo y colecciones biológicas, Editorial AMA, Havana, Cuba, pp: 376-411.

4. Rodríguez Schettino L, Mancina CA, Rivalta V (2013) Reptiles of Cuba: checklist and geographic distributions. Smithsonian Herpetological Information Service 144: 1-96.

5. Rodríguez Schettino L (2012) Reptiles. In: González Alonso $\mathrm{H}$, Rodríguez Schettino L, Rodríguez A, Mancina CA, Ramos Garcia I (Eds.), Editorial Academia, Havana, pp: 93-95.

6. Henderson RW, Powell R (2009) Natural History of West Indian Reptiles and Amphibians. University Press of Florida, Gainesville, Florida, USA, pp: 487.

7. Fong A, Díaz LM, Viña N (2005a) Anfibios y reptiles. In: Fong A, Maceira D, Alverson WS, Shopland JM (Eds.), Cuba: Humboldt. Rapid Biological Inventories. Report 14. The Field Museum, Chicago, USA, pp: 9298.

8. Fong A, Viña Dávila N, Viña Bayés N (2005b) Amphibians and reptiles of the altiplanicie del Toldo. In: Fong A, Maceira D, Alverson WS, Shopland JM, (Eds.), Cuba: Humboldt. Rapid Biological Inventories. Report 14. The Field Museum, Chicago, USA, pp: 98101.

9. Estrada AR, Ruibal R (1999) A review of Cuban Herpetology. In: Crother, B. (Ed.), Caribbean Amphibians and Reptiles. Academic Press. San Diego, USA, pp: 31-62.

10. Rodríguez Schettino L, Rivalta V (2003) List of species. In: Rodríguez Schettino L (Ed.), Anfibios y Reptiles de Cuba. UPC Print, Vaasa, Finlandia, pp: 162-165.

11. Estrada AR (2012) The Cuban Archipelago. In: Powell R, Henderson R (Eds.), Island lists of West Indian amphibians and reptiles. Bulletin of the Florida Museum of Natural History FL, USA, 51(2): 85-166.

12. Groff LA, Marks SB, Hayes MP (2013) Using Ecological Niche Models to Direct Rare Amphibian Surveys: A Case Study Using Oregon Spotted Frog (Rana pretiosa). Herpetological Conservation and Biology 9(2): 354-368. 


\section{International Journal of Zoology and Animal Biology}

13. Chefaoui RM, Hortal J, Lobo JM (2005) Potential distribution modelling, niche characterization and conservation status assessment using GIS tools: a case study of Iberian Copris species. Biological Conservation 122(2): 327-338.

14. Chase JM, Leibold MA (2003) Ecological Niches: Linking Classical and Contemporary Approaches. University of Chicago Press, Chicago, IL, USA.

15. Velazco K (2017) Valoración del efecto del cambio climático sobre la distribución de especies cubanas del género Sphaerodactylus (Sauria: Sphaerodactylidae). Thesis in option of Master degree in Zoology and Animal Ecology [inedit]. Havana University, Havana, Cuba, pp: 136.

16. Gutiérrez RD, Rivero M (1997) Minigeography of Cuba. Scientific-Technical Editorial, Havana, Cuba, pp: 142.

17. Díaz LR, Gutiérrez GO, Sánchez EA, Hernández JR, Propin E (1998) New National Atlas of Cuba. Cuban Institute of the Academy of Sciences of Cuba, Havana, Cuba.

18. Mateo J, Acevedo M (1989) Physical-geographical regionalization. Scale 1: 3,000,000. In: Oliva G, Lluís E, Sánchez EA (Eds.), New National Atlas of Cuba, Academy of Sciences of Cuba, Cuban Institute of Geodesy and Cartography, National Geographic Institute of Spain, Madrid, Spain, pp: 12-21.

19. Capote RP, Berazaín R (1984) Classification of vegetation formations of Cuba, Revista del Jardín Botánico Nacional 5(2): 1984.

20. Phillips SJ, Anderson RP, Schapire RE (2006) Maximum entropy modeling of species geographic distributions. Ecol Model 190: 231-259.

21. ESRI (2011) ArcGIS Desktop: Release 10. Redlands, CA: Environmental Systems Research Institute.

22. Anderson RP, Raza A (2010) The effect of the extent of the study region on GIS models of species geographic distributions and estimates of niche evolution: preliminary tests with montane rodents (genus Nephelomys) in Venezuela. Journal of Biogeography 37(7): 1378-1393.

23. Barve N, Barve V, Jimenez-Valverde A, Lira-Noriega A, Maher SP, et al. (2011) The crucial role of the accessible area in ecological niche modeling and species distribution modeling. Ecol Model 222(11): 1810-1819.

24. Hijmans RJ, Cameron SE, Parra JL, Jones PG, Jarvis A (2005) Very high resolution interpolated climate surfaces for global land areas. Int J Climatol 25(15): 1965-1978.

25. Stat Soft Inc (2007) STATISTICA (data analysis software system), version 8.0.

26. Hardle W, Simar L (2007) Applied Multivariate Statistical Analysis. Springer Berlin, Heidelberg, New York, USA.

27. Peterson AT, Soberón J, Pearson RG, Anderson RP, Martínez Meyer E, et al. (2011) Ecological Niches and Geographic Distributions. Princeton University Press, Princeton, New Jersey, USA, pp: 314.

28. Jiménez Valverde A (2012) Insights into the area under the receiver operating characteristic curve (AUC) as a discrimination measure in species distribution modeling. Global Ecol Biogeogr 21(4): 498-507.

29. Lobo JM, Jiménez-Valverde A, Real R (2008) AUC: a misleading measure of the performance of predictive distribution models. Global Ecol Biogeogr 17(2): 145151.

30. Broennimann 0, Thuiller W, Hughes G, Midgley GF, Alkemades JMR, et al. (2006) Do geographic distribution, niche property and life form explain plants' vulnerability to global change? Global Change Biol 12(6): 1079-1093.

31. Warren DL, Glor RE, Turelli M (2010) ENMTools: a toolbox for comparative studies of environmental niche models. Ecography 33(3): 607-611.

32. Thuiller W, Lavorel S, Araujo MB, Sykes MT, Prentice IC (2005) Climate change threats to plant diversity in Europe. Proc Natl Acad Sci USA 102(23): 8245-8250.

33. Hammer $\emptyset$, Harper DAT, Ryan PD (2001) Past: Paleontological Statistics Software Package For Education And Data Analysis. Palaeontologia Electronica 4(1): 1-9.

34. Davis JC (1986) Statistics and Data Analysis in Geology. John Wiley \& Sons Inc., New York. 


\section{International Journal of Zoology and Animal Biology}

35. Snedecor GW, Cochran WG (1977) Statistical Methods applied to experiments in agriculture and biology $5^{\text {th }}$ (Edn.), Iowa State University Press, Ames, Iowa, USA, pp: 251.

36. Broennimann 0 , Treier UA, Müller Schärer $\mathrm{H}$, Thuiller W, Peterson AT, et al. (2007) Evidence of climatic niche shift during biological invasion. Ecology Letters 10(8): 701-709.

37. Warren DL, Seifert SN (2011) Ecological niche modeling in Maxent: the importance of model complexity and the performance of model selection criteria. Ecol Appl 21(2): 335-342.

38. Nakazato T, Warren DL, Moyle LC (2010) Ecological and geographic modes of species divergence in wild tomatoes. American Journal of Botany 97(4): 680693.

39. Zaniewski AE, Lehmann A, Overton JM (2002) Predicting species spatial distributions using presence-only data: a case study of native New Zealand ferns. Ecological Modelling 157(2-3): 261280.

40. Wollan AK, V Bakkestuen H, Kauserud G, Gulden, Halvorsen R (2008) Modelling and predicting fungal distribution patterns using herbarium data. Journal of Biogeography 35(12): 2298-2310.

41. Elith J, Leathwick JR (2009) Species distribution models: ecological explanation and prediction across space and time. Annu Rev Ecol Evol Syst 40: 677-697.

42. Raxworthy CJ, Ingram CM, Rabibison N, Pearson RG (2007) Applications of ecological niche modeling for species delimitation: a review and empirical evaluation using day geckos (Phelsuma) from Madagascar. Syst Biol 56(6): 907-923.

43. Buermann W, Saatchi S, Smith TB, Zutta BR, Chaves $J A$, et al. (2008) Predicting species distributions across the Amazonian and Andean regions using remote sensing data. Journal of Biogeography 35(7): 1160-1176.

44. Urbina Cardona JN, Loyola RD (2008) Applying niche-based models to predict endangered-hylid potential distributions: are neotropical protected areas effective enough? Tropical Conservation Science 1: 417-445.

45. Elith J, Graham $\mathrm{CH}$, Anderson RP, Dudyk M, Freer S, et al. (2006) Novel methods improve prediction of species' distributions from occurrence data. Ecography 29(2): 129-151.

46. Clusella Trullas S, Blackburn TM, Chown SL (2011) Climatic predictors of temperature performance curve parameters in ectotherms imply complex responses to climate change. Am Nat 177(6): 738751.

47. Hedges SB (2017) Diploglossus. Caribherp, West Indian amphibians and reptiles.

48. Fong A (2017) Diploglossus delasagra. The IUCN Red List of Threatened Species 2017: e. T75167849A7517 1976z.

49. Fong A (2017) Diploglossus nigropunctatus. The IUCN Red List of Threatened Species 2017: e.T75168161A75171986.

50. Martínez Reyes M, Moreno LV (2003) Lagartos habitantes de los suelos. In: Rodríguez Schettino L, (Ed.), Anfibios y Reptiles de Cuba, UPC Print, Vaasa, Finland, pp: 90-97.

51. Schwartz A, Henderson RW (1992) Amphibians and Reptiles of the West Indies. Descriptions, Distributions, and Natural History. The Quarterly Review of Biology 67(3).

52. Fong A (2012) Diploglossus nigropunctatus. In: González Alonso H, Rodríguez Schettino L, Rodríguez A, Mancina CA, Ramos Garcia I, (Ed.), Libro Rojo de los Vertebrados de Cuba, Editorial Academia, Havana, pp: 97-98.

53. Losos JB (2008) Phylogenetic niche conservatism, phylogenetic signal and the relationship between phylogenetic relatedness and ecological similarity among species. Ecol Lett 11(10): 995-1003.

54. Fong A (2012) Diploglossus garridoi. In: González Alonso H, Rodríguez Schettino L, Rodríguez A, Mancina CA, Ramos Garcia I. (Eds.), Libro Rojo de los Vertebrados de Cuba. Editorial Academia, Havana, Cuba, pp: 96-97.
Velazco-Pérez K and Estrada-Piñero FN. Analysis and Comparison of the Ecological Niche of Two Endemic Species of the Genus Diploglossus (Sauria: Diploglossidae). Int J Zoo Animal Biol 2019, 2(3): 000157.
Copyright@C Velazco-Pérez K and Estrada-Piñero FN. 